\title{
Evolution of a Surgeon: A 40-Year Perspective
}

\author{
John C. Bowen
}

Received: 14 October 2008 / Accepted: 14 October 2008 / Published online: 30 October 2008

(C) 2008 The Society for Surgery of the Alimentary Tract

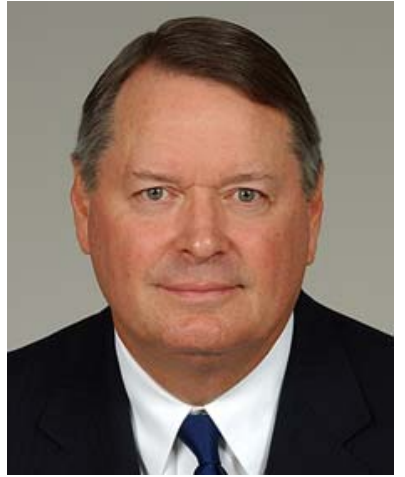

I have looked forward to this day with anticipation and some trepidation for nearly 2 years. When I first joined the SSAT, about 30 years ago, I was then and am now in awe of the SSAT, and for me it has never lost its luster. When I was inducted, some of the founders were still active, providing me with special memories of those early days, and over the years, I have made many friends and acquaintances through my involvement in the SSAT. In a sense I grew up in this organization.

Several SSAT members have served as role models for me over my career and as such were my heroes: Wally

This article was perviously published without the photograph of Dr. Bowen in Journal of Gastrointestinal Surgery Volume 12, Number 10 (October 2008). It is reproduced here in its entirety.

Presidential Address at the annual meeting of the Society for Surgery of the Alimentary Tract, San Diego, CA, May 19, 2008.

J. C. Bowen $(\bowtie)$

Department of Surgery, Ochsner Clinic Foundation,

1514 Jefferson Highway,

New Orleans, LA 70121, USA

e-mail: jbowen@ochsner.org
Ritchie, Frank Moody, and Bill Silen come immediately to mind. Each in his own way was a help to me, willing to provide advice, support, or encouragement for a young surgeon trying to understand the traditions and pitfalls, as well as the opportunities of academic surgery. Other SSAT members who have contributed to my professional development include Ted Copeland, Joe Fischer, Stan Dudrick, Bernie Jaffe, Lou Flint, Jim Thompson, Isidore Cohn, Tom DeMeester, and the late Jim Thompson, to name just a few. And I cannot fail to mention Larry Cheung and Bing Rikkers, Frank Moody's disciples in their Utah days, who were always good comrades.

My last words of appreciation go first to Dr. Eugene Jacobson. Gene, when he was the first Professor and Chairman of Physiology at the new University of Texas Medical School in Houston, took me into his GI laboratory, despite the fact that I was a surgeon, and turned a neophyte into a fairly competent investigator. I understood that I would never win a Nobel Prize, but he managed to train me well enough for me to be awarded several NIH ROI grants, a good start to any young surgeon's career. For that I thank Gene and also Wally Ritchie who first whetted my appetite for bench research during my time at the Walter Reed Army Institute of Research.

Last, but not least, I want to recognize Dr. John Ochsner who recruited me to the Ochsner Clinic in 1976 and who has served ever since as my role model, mentor, and friend. John is truly one of the great surgeons of the twentieth century. I have been very lucky to follow behind a man of such extraordinary ability, character, and commitment to surgery and to his patients.

Speaking of research and great surgeons, I recently ran across these words: "...the achievement of the surgeon and his assistants becomes one of the greater glories of science... in the operating room all results of the most 
improbable reaches of research, all the immense accumulation of medical knowledge are drawn upon in a determined drive towards... preservation of one human life." 1

Those words were written in an article that appeared in Time Magazine on May 3, 1963 entitled, "The Best Hope of All." A few months later I entered medical school and, perhaps naively, began a quixotic journey to become a doctor. The article in Time was written to extol the new "modern surgeon" who pursues knowledge to establish a scientific foundation for surgical treatment and who dares to perform procedures so radical that they were almost unimaginable a few years before. In the same article Dr. Donald Effler, the Cleveland Clinic surgeon, was quoted as saying, "A great surgeon must have a fierce determination to be the leader in his field. He must have a driving ego, a hunger beyond money. He must have a passion for perfectionism." The surgeon luminaries of the twentieth century, including many of our predecessors in SSAT, possessed powerful personalities and fierce determination in order to achieve success and to further the development of surgery. Throughout most of the twentieth century, the image of a surgeon was that of a commanding presence, capable of controlling all facets of patient care, a leader the Germans called a geheimrat. Advances required strong personalities with great self-confidence, ego strength, and limitless perseverance.

Today the surgeon's image is changing as a result of many factors - social, organizational, legal, economic, and political. For the most part, these forces are beyond the control of the surgeon. Today's surgeon, of necessity, must fit in with a team of health care professionals and interact collegially with them to be successful.

Becoming a part of a team with other specialists has made it impossible for a surgeon to fulfill the traditional role of "master of the ship." It's acknowledged that a surgeon should understand and be aware of every aspect of his patient's disease and care, but in fact, many others play important roles and make it impractical to retain complete control over the patient's care.

Nevertheless, it is the surgeon who stands before the patient and draws up the contract that permits the surgeon and the team to embark on a plan to correct a surgical problem. And it is the surgeon to whom the patient has entrusted his life and welfare.

Surgeons understand the human cost of failure better than any other professional group in our society. We know that the only thing that really counts is results, i.e., solving a problem with the least cost of human suffering and with optimal benefit to the patient. The commitment to surgery is the defining event for the patient and for the surgeon. Style and artifice are useless if not effective; and founts of knowledge and intellectual speculation are useless unless at the defining moment they provide clarity, thought, and direction to guide the surgeon's hand.

A new distraction is now foisted on a surgeon as a result of rapid communication. The nearly instantaneous spread of new ideas, not only to the medical community but also to the public, brings pressure on the contemporary surgeon to wade through a morass of information, released unedited and untested into the public awareness. The pressure to be au courant, to know the latest claims and counterclaims, and to be able to discuss them with the next patient who walks in your office can be a demanding exercise. So much of what is available to the public is, at best, half-baked, sometimes untrue, and often misunderstood to the point it can become a major impediment to winning a patient's confidence. Unfounded claims can create unrealistic expectations that do not account for the full range of possible outcomes and make obtaining informed consent difficult. The public is ill-equipped to evaluate medical information, prioritize its importance, and make rational decisions.

As surgeons, we cannot become deluded by claims of what could or should be, and as surgeons we face our own stern realities in which events may unfold unpredictably and absolute control is an illusion. This reality now blends into today's world where statistics, algorithms, and consensus opinions tell us what others say we should achieve. This places pressure on every surgeon to be risk averse. Unfortunately, many problems we face are complex, their solutions involve risk for both the patient and the surgeon, and statistical probabilities are not always achievable. We struggle to deal with outsiders from the secular world who want to control and quantify the unquantifiable, thus deterring performance and inhibiting innovation. How and if this tension can be resolved remains an open question.

Managers in today's world believe process and controls produce a better product. I suppose it was just a matter of time until the "organization man" that we derided in the 1960s and 1970s turned his managerial skills toward the unbowed world of medicine. This raises the question whether surgeons have to become subservient to the organization man to survive. Will "best practices" and treatment "guidelines" retard innovation and produce mediocrity or will they provide a constructive framework for producing better outcomes? Standardization of routine processes insures safety from technical and administrative errors, to be sure. Computer programs have already improved our ability to collate information and to track and coordinate patient care. However, fear of intrusive oversight and misuse of information can create a "gotcha" mentality that will produce a chilling effect on surgical decision making. Information that can be manipulated against anyone who dares to challenge orthodoxy confers unfettered power on the organization man. Fear breeds 
temerity, a surgeon's enemy when there is a need to make decisions, act with partial information, or to use experiential judgment.

Where then will the surgeon leaders of the twenty-first century come from? Will they be as talented, imaginative, and determined as the personalities attracted to our profession in the past? Are these types needed or even wanted in the new world order? In her book The Scalpel's Edge, ${ }^{2}$ Pearl Katz opines that the new surgical heroes may be those who admit doubt and uncertainty, communicate sensitively with patients in an effort to have patients participate in decision making, communicate openly with their colleagues, and take risks not for their patients but with their patients. Katz's vision of the surgeon's role in the future, as seen through the eyes of a cultural anthropologist, bespeaks a humanistic adaptation that is already underway. It appears that the boldness and rugged individualism that characterized so many of our surgeon pioneers will have to be sublimated and further modified for the next generation of surgeons to be effective leaders.

The technological explosion in American surgery began in 1989 when the application of the laparoscope to cholecystectomy was proven to be not only doable but teachable to thousands of trained surgeons. Its advantages over standard surgery caused a stampede to learn the technique.

In my case, I saw two laparoscopic cholecystectomies performed in a small community hospital in early 1990. And within a few weeks, I had performed my first laparoscopic cholecystectomy, having cobbled together the rudimentary equipment. This was as close to see one, do one, teach one as it gets. From that experience, I developed renewed respect for our pioneering predecessors who performed much more risky procedures with even less guidance under even more primitive conditions. Because it could be performed by thousands of surgeons hundreds of times and because it is so perfectly amenable to minimally invasive techniques, laparoscopic cholecystectomy did more, in my opinion, to advance all of surgery, and especially gastrointestinal surgery, than any other surgical innovation in my professional life.

The parallel development of small, modular, digital computers was a fortuitous congruence that led visionaries to see the great potential created by combining minimally invasive surgery with the power of computerized control. The impact of these developments is so far reaching that they have truly created a new paradigm affecting every aspect of modern surgery. A partial list of impacted areas would include training, workforce requirements, facilities, economics, levels of specialization, certification and credentialing, litigation, reimbursement patterns, and not the least affected-patients' expectations.

Nevertheless, the technological developments of the past 20 years, while providing a thrust to the future of surgery that I never dreamed of, have produced a host of complex problems. Among those concerns is the future of general surgery. As early as 1991, in the title of his SSAT Presidential address, William Silen implored, "Where Have the General Surgeons Gone?"3 He presciently predicted that as the number of specialists and consultants increase, costs would escalate, rapport with the patient and trust in the physician would erode, malpractice litigation would escalate, and college students' interests in medical careers would wane. Have not all of his predications come to pass?

The extent of the threat to general surgery as a specialty began to come into focus just as the new millennium began. The AMA Physician Database showed a decline of just over 2,600 general surgeons in 4 years, a fall in absolute numbers from 27,509 in 1998 to 24,902 in 2002. This occurred despite a population growth in the U.S. of approximately 25 million each decade since 1970 . Concomitantly, the production of general surgeons in the U.S. over the past 25 years has been remarkably constant at an even 1,000 per year. This has continued through the match in 2007 when over $99 \%$ of 1,055 positions were filled.

There are two significant and relevant demographic factors that are noteworthy, although their impact on the future of general surgery is uncertain. The first is that in 2001 the percentage of positions filled by U.S. medical school graduates fell below $90 \%$ for the first time in history. ${ }^{4}$ And in 2007 the percentage filled by U.S. graduates fell below $80 \%$. This pattern is not universal for all specialties. For example, anesthesiology trends are the reverse, having filled only $30 \%$ of their slots in 1996 (their nadir) and increasing dramatically to $98 \%$ filled with $78 \%$ U.S. graduates in 2007. Likewise, diagnostic radiology filled only $50 \%$ in 1996 compared to $100 \%$ in 2007 with $89 \%$ U.S. graduates. Clearly, there is a declining interest in general surgery and its related specialties among U.S. medical graduates.

The second demographic of note is that women now comprise over $50 \%$ of medical school graduates. And, there has been a drop of over $50 \%$ in the total number of men applying to medical school since 1974. Bucking these trends, general surgery remains a white male dominated specialty with little more than $20 \%$ being females. The gender factor is widely assumed to have a negative impact on the surgical workforce by limiting the available candidates for residency because of lifestyle issues and by reducing the availability of practicing general surgeons due to a greater likelihood of women choosing to interrupt or shorten their careers.

These data augur for a further decline in the general surgery workforce that will limit available candidates for further specialty training. Because the number of federally funded entry positions in general surgery is capped by the 
Balanced Budget Act of 1997 at about 1,000 per year, competition for candidates to fill subspecialty slots will be fierce. And, it is not surprising that several specialties have already successfully petitioned the American Board of Surgery to allow them to accept candidates after only 3 or 4 years of general surgery training.

But what explains the actual decline in the number of practicing general surgeons that is already occurring? Dr. David Cosman, a practicing vascular surgeon in Los Angeles, writes an opinion column in General Surgery News expressing his views on a wide range of subjects including medical economics, politics, practice, and the future of surgery. He recently opined that "there is a rising tide of physician dissatisfaction in this country.... Demoralized by decreased reimbursements, endless regulatory rituals, useless compliance exercises, and a distrustful patient population, physicians are on the ledge, and it won't take much more to push them over the edge."

This sentiment is shared by more and more practicing surgeons who don't see a way out of the quagmire they find themselves in. Reimbursement for surgical services in real dollars is approximately $30 \%$ of what it was 15 years ago, and yet practice overhead has more than doubled largely due to inflation, regulatory mandates, rising insurance premiums, and administrative cost increases. In a statement to a senate committee this year (Senate Committee on Health, Education, Labor and Pensions, February 12, 2008) the American College of Surgeons, addressing health care workforce issues for the future, concluded that "the single most important factor shaping the surgical workforce issue is declining reimbursement." These concerns beg the question of whether it is too much to ask that present and future surgeons have some hope of prosperity and security. Is it any wonder that more and more general surgeons are either retiring early or seeking another career?

One thing is certain; the workforce is declining as the American populace grows larger and older. These kinds of trends take decades to produce and decades to reverse. Unfortunately, there is no plausible evidence to suggest that the public or our elected officials perceive a physician shortage or, more specifically, a shortage of surgeons. The exceptions to this reality are limited to rural areas that have little or no service and lack the political influence to affect public policy. Surgeons need formidable public relations and formidable political advocacy to stabilize and hopefully improve reimbursement. So far, as a profession, we have not developed effective political representation, and, unfortunately, we have no natural allies to champion our cause. Alone we have little political leverage. This is not a condemnation of our surgical societies, all of which were founded for educational, not political purposes. Furthermore, traditional professional societies may not be the best means through which to achieve political influence. Yes, the American public does think there is a health care crisis, as the media and opinion polls remind us daily, but the concern of the American public is solely about their individual cost and their access to care, not surgeon's pay and lifestyle.

On the production end of the equation, general surgery residency numbers remain constant for now only because the number of international applicants remains robust. Basically, surgery positions fill with qualified U.S. applicants and then top off with qualified foreign graduates. The decline in U.S. seniors choosing careers in surgery augurs poorly for the future, and the increasing reliance by American training programs on foreign medical graduates to fill positions makes the continued supply of surgical specialists tenuous.

This concern, first brought to prominence by the 2001 general surgery match results, has been the subject of much discussion. After reviewing dozens of articles written about the disaffection of graduating seniors for general surgery, and after trying to digest reams of demographic data, it seems fairly transparent to me: Today's contemporary generation (or Generation X, defined as anyone born after 1965 ) is not as attracted to general surgery (or its subspecialties) because they see in them less relative value as compared to other specialties and other professions. The simplistic explanation has been to blame "lifestyle issues." This catch phrase implies that the younger generation is not as committed or as willing to work as previous generations. The notion that if surgeon educators could just make surgical training more attractive and user friendly, and things will get better, is frankly naive. Maybe some medical students have been scared off because they see how long and hard surgeons work or how stern and demanding they can be at times. Clearly, some react negatively to the surgical ethos. Unfortunately, the cause of disaffection is much deeper and not so easily corrected.

One important influence on a career's attractiveness is financial. A former medical director at the Ochsner Clinic said, "when someone says it's not about the money, it's the principle of the thing, it's always about the money." Professor Michael Porter of the Harvard Business School, at this year's annual meeting of the American Surgical Association, ${ }^{6}$ characterized health care as a "zero sum competition", meaning that all the participants in the healthcare community are pitted against each other to carve out more value at the expense of others. Therefore, is it any wonder that the next generation is questioning commitment to a specialty whose status has become financially compromised and whose services, especially in general surgery, have been, I think, intentionally devalued? Isn't fair compensation a reasonable expectation for years invested in a surgeon's education, for the stresses and interruptions in family life, and for a life of commitment to 
the frailties of others? How can anyone expect to have balance in their life if they are chronically overworked and financially strapped?

Fortunately, there are still highly motivated and talented candidates who are willing to pay the price necessary to be molded into what is one of the most personally rewarding professions that exists, that of a surgeon. The intangible rewards are still among the most satisfying of any profession I know. But the reality is that the life of a surgeon is not easy and it's not always possible to plan your practice around your personal life. It would be misleading to promise surgical candidates a rose garden. I would much prefer to train young surgeons with realistic expectations, committed to a life of professional attainment and responsibility, than to do anything to weaken the fabric of our profession. And it is incumbent upon those of us in leadership roles to make certain that we stand steadfast against any attempts to compromise or minimize the requirements necessary to become a surgeon. If we overreact to a few poor years in the match and if we begin to undermine the basic tenets of surgical education that have been shown to be tried and true for over 100 years, we will do a lasting disservice to future generations.

We, in our professional capacity, can do very little to change the practice environment that is eating away at so many of our colleagues. The forces producing practice dissatisfaction are, for the most part, beyond our control and reflective of political and societal ills that will require a sea of change to rectify. But, we can take seriously and responsibly our stewardship of the next generation of surgeons. To that end, we must protect the depth and breadth of surgical experience as the bedrock of training.

The science of experience teaches us that mastering most complex human endeavors requires a minimum of 10 years' experience. Surgeon educators have and will continue to develop new methods to teach complex subjects, but there is a limit to how fast the human mind can absorb large quantities of information, synthesize it, and apply it to an almost infinite number of circumstances. Furthermore, training parameters must be designed to adequately train the slowest, not just the quickest and most facile. When dealing with human life we are obligated to maintain training goals that aim, as in aviation, for zero defects. In medicine, in contrast to other professions such as civil engineering, solutions to urgent and complex problems must be acted on in real time, often with partial information. Surgeons must be trained to manage the worst scenarios and to confront the unexpected. The human condition comes in limitless variations, making it essential that each surgeon has the capacity to respond flexibly and reflexively. Professional discipline and technical skills are gained through long hours of repetition and through struggling under adverse circumstances. William Halsted and other great surgeon educators of the twentieth century understood and stated explicitly that it takes time and years of experience to train a surgeon.

It is popular today to appear flexible and understanding. But in my 40 years in surgical education, as a trainee or trainer, I can see no justification for being anything but demanding and rigorous in the design of the training process. In surgery, the only acceptable performance goal is the best that can be achieved for each and every patient. Nothing less is acceptable. This can only be accomplished if each surgeon is broadly and expertly trained and experienced.

While 10 years is probably a minimum required to achieve expertise in most complex fields, including surgery, more and more experience alone is not a guarantee of success. Gaining experience is only the starting point. Anders Ericsson, the editor of the Cambridge Handbook of Expertise and Performance, ${ }^{7}$ states, "The number of years experience in a domain is a poor predictor of performance." This observation is particularly relevant to the experienced and mature surgeon. Ericsson holds that rather than through more and more experience, sustained performance is achieved through what he calls "dedicated exertion", i.e. repeatedly practicing the most difficult tasks that lead to excellence and consistent performance. If a task gets easy and the mind wanders, routine tasks may be executed mindlessly and mistakes occur.

A recent study from Harvard, for example, reported the causes of surgical technical errors that had resulted in malpractice claims. ${ }^{8}$ The majority (or 73\%) involved experienced surgeons, and $84 \%$ occurred in routine rather than advanced procedures requiring special training. Therefore, successful performance requires more than experience or "time in grade" in U.S. Army jargon, but continuing focus on decision-making and constant awareness in routine operations for the occurrence of complex circumstances.

The importance of experience in training leads me to a few thoughts on the design of surgical training in the future. You have already deduced that I am "old school." That I feel surgical training must be, of necessity, long enough and rigorous enough for the trainee to acquire not only practical experience but also to acquire intangibles like mental and emotional discipline. In my opinion, early specialization after only 3 years of general surgery, as has been proposed, ${ }^{9}$ will produce a surgical workforce of narrowly trained specialists who lack the foundation, maturity, and breadth of experience to meet the challenges they will surely confront in their careers. If the perceived disaffection of senior medical students is used as a reason to reduce the rigor of general surgery training prior to specialization in an attempt to make surgery more alluring, it will severely diminish the effective workforce of qualified general surgeons. An unintended consequence will be to create several tiers of qualification and credentialing that will be a 
nightmare to administer and unravel. Credentialing committees will be forced to rely on formulas to determine competency, moving standards toward the lowest common denominator. Litigation over qualifications will ensue, producing a morass that the courts are ill prepared to adjudicate. Gaps in coverage of specific conditions will emerge, and hospitals, as they become increasingly reliant on fragmented specialists, will have to enlarge their staffs to maintain continuity of care. ${ }^{10}$ Who will be empowered to convene the specialists to assign ultimate responsibility for the whole patient? I fear that into this void will lead an opportunist, perhaps with little or no surgical experience, to seize the role of ringmaster. All of this will magnify the anticipated workforce shortages, and the redundancy of specialists will lead to rising costs. In the end, continuity of care will be sacrificed and patients will suffer.

Thirty-five years ago a Yale psychologist, Irving Janis, published an essay in the Yale Alumni Magazine to explain how a group of intelligent people working together to solve a problem can sometimes arrive at the worst possible answer. ${ }^{11}$ He called his radical new theory "group think." The consequences of such an error can be devastating. A minor consequence would be that a proffered solution simply delays resolution of a problem. More serious consequences can lead to tragic outcomes such as the Bay of Pigs fiasco, the escalation of the Vietnam War, or now, the prosecution of the Iraqi War.

Today, group think is studied in military colleges, political science classes, business schools and academia. In response to criticism regarding decisions leading up to the Iraqi War, the CIA announced it has initiated new procedures to minimize the risk of "group think." John A. Kringan, head of the CIA's Directorate of Intelligence, has outlined new procedures setting up "alternative analysis" teams to guard against decisions going off in the wrong direction for the wrong reasons. This process provides for an external authority to test the assumptions and conclusions of the group before potentially damaging or irreversible action is taken.

My concern is that the future of surgical training, its basic premises and format, be examined and debated, and any proposed changes subjected to the equivalent of an alternative analysis before anything is done that could permanently weaken the foundation of surgery in America. A minimum of 5 years of surgical training before specialization should be retained as a foundation until all the consequences of compressed general surgery training have been explored.

Tomorrow's surgeon is faced with mastering more knowledge, not less; more complexity, not less; and the hard-earned lessons of the past must be passed on to the next generation. It is crucial that we shape the scope of knowledge and experience that will be required of future surgeons and that we not be unduly influenced by transitory exigencies. In the end we cannot control all the forces buffeting our society, but we can and should control the fundamental qualifications necessary to fulfill our responsibility to the future of our profession. And above all, we must instill in future surgeons, in Dr. Effler's words, "a passion for perfectionionism." Nothing less will do.

"Be not the first by whom the new are tried

Nor yet the last to lay the old aside"

Alexander Pope

Essay on Criticism, 1711

\section{References}

1. The best hope of all. Time Magazine, May 3, 1963.

2. Katz P. The scalpel's edge. Boston: Allyn and Bacon, 1999.

3. Silen W. Where have the general surgeons gone? Am J Surg 1992;163(1):2-4. doi:10.1016/0002-9610(92)90243-K.

4. National Resident Matching Program. http://www.nrmp.org.

5. Cosman D. Answering the call. Gen Surg News 2008;35(3):1,311,34 .

6. Porter M. Forum on "Value-Based Health Care Delivery" presented April 25, 2008 at the annual meeting of the American Surgical Society in New York, New York.

7. Ericsson A, ed./ln Cambridge Handbook of Expertise and Expert Performance. New York: Cambridge University Press, 2006.

8. Regenbogen SE, Greenberg CC, Studdert DM, Lipsitz SR, Zinner MJ, Gawande AA. Patterns of technical error among surgical malpractice claims: an analysis of strategies to prevent injury to surgical patients. Ann Surg 2007;246(5):705-711.

9. Debas HT, Bass BL, Brennan MF, et al. American Surgical Association Blue Ribbon Committee Report on Surgical Education: 2004. Ann Surg 2005;241(1):1-8.

10. Stitzenberg KB, Sheldon GF. Progressive specialization within general surgery: adding to the complexity of workforce planning. J Am Coll Surg 2005;201(6):925-932. doi:10.1016/j.jamcollsurg. 2005.06.253.

11. Lassila KD. A brief history of group think. Yale Alumni Magazine, Jan/Feb 2008, pp 59-61. 